\title{
A novel approach to flood risk assessment: the Exposure-Vulnerability matrices
}

\author{
Susanna Naso ${ }^{1, a}$, Albert S. Chen ${ }^{2}$, Giuseppe T. Aronica ${ }^{1}$ and Slobodan Djordjević ${ }^{2}$ \\ ${ }^{1}$ Dipartimento di Ingegneria, University of Messina, Contrada Di Dio, 98166 Villaggio S. Agata - Messina, Italy \\ ${ }^{2}$ Centre for Water Systems, University of Exeter, Harrison Building, Streatham Campus, University of Exeter, North Park Road, Exeter - \\ EX4 4QF, UK
}

\begin{abstract}
The classical approach to flood defence, focused on reducing the probability of flooding through hard defences, has been gradually substituted by flood risk management approach, which accepts the idea of coping with floods, and aims at reducing both probability and the consequences of flooding. In this view, the concept of vulnerability becomes central, such as the (non-structural) measures for its increment. However, the evaluations for the effectiveness and methods of non-structural measure and the vulnerability are less studied, compared to the structural solutions. In this paper, we adopted the Longano catchment in Sicily, Italy, as the case study. The methodology developed in the work enabled a qualitative evaluation of the consequences of floods, based on a crisscross analysis of vulnerability curves and classes of exposure for assets at risk. A GIS-based tool was used to evaluate each element at risk inside an Exposure-Vulnerability matrix. The construction of an E-V matrix allowed a better understanding of the actual situation within a catchment and the effectiveness of non-structural measures for a site. Referring directly to vulnerability can also estimate the possible consequences of an event even in those catchments where the damage data are absent. The instrument proposed can be useful for authorities responsible for development and periodical review of adaptive flood risk management plans.
\end{abstract}

\section{Introduction}

The concept of risk implies a transition from the classical approach of defending a territory from flood hazard, through structural measures that modify the characteristics of the flood event, to the approach of reducing flood risk, through structural and non-structural measures that act on both flood hazard and its consequences. The EU Directive underlines the importance of prevention-oriented approaches, adopting early-warning systems, flood forecasting techniques, and land use regulation.

The use of prevention measures that do not interfere on flood's features requires the elaboration of methodologies and strategies to verify their effectiveness. All over the world, public governmental bodies and academics published some studies on the effectiveness of non-structural measures [1-3], but the lack of data on it (or their coarseness) makes their reliability hard to know. The variable in risk equation [4] that describes the attitude of a territory in suffering impact of an hazardous event is vulnerability, defined as "the characteristics and circumstances of a community, system or asset that make

\footnotetext{
a Corresponding author: snaso@unime.it
}

it susceptible to the damaging effects of a hazard" [5]. The term "vulnerability" has actually different interpretations, as existing epistemological traditions in various research areas with different objectives [6-8]. Fuchs et al. [9] summarised these definitions of vulnerability with respect to natural hazards research. From a natural science perspective, studies on vulnerability focus on the susceptibility of physical systems in areas at risk to natural processes. Vulnerability is therefore considered as loss degree or percentage of damage that assets in areas at risk may suffer, which depends not only on hazard attributes, but also on the intrinsic characteristics of the affected element.

The definition of vulnerability is often confused with the one of exposure, which is defined as the number of assets being present in endangered areas distinguished per typologies [5]. Studies related to flood vulnerability assessment are few because the uncertainty involved is difficult to quantify. In fact, although different damage assessment methods have been developed [10-14], the lack of high-quality essential data remains as the main obstacle to the derivation of uncertainties in ex-ante analysis. 


\section{Methodology}

In this paper, we have developed a new methodology to assess flood risk for buildings based on their exposure classes and the relationship between flood depth and vulnerability. The goal is to describe flood consequences or flood risk in watersheds where vulnerability data do not exist or their quality makes them unreliable.

We considered the relation of vulnerability as the impact of natural hazards, generally measured in terms of damages or losses, and assessed the vulnerability as the expected loss degree of an element (or set element) at risk as a consequence of a hazardous event $[15,16]$. Meanwhile, we further normalised the vulnerability to a value between 0 and 1 , as the expected degree of loss varying from no damage to complete disruption. On the contrast, we regarded exposure as the pure identification of assets at risk and attributed the nominal value of each element based on the function of its strategic, economic and functional role. No monetary value was associated to buildings.

Our methodology includes four steps. At first, a hydraulic modelling is applied to derive the hydrodynamic characteristic of the flood event studied. The second step is determining the Exposure based on the building categories provided in the Flood Risk Plan for Sicily [17]. The third step is deriving vulnerability curves for different buildings in Sicilian territory through a synthetic approach. Finally, the vulnerability assessment for different Exposure categories, referring to a flood event occurred in Barcellona Pozzo di Gotto (North-East Sicily, Italy): the results have been reported in an Exposure-Vulnerability matrix, allowing an immediate understanding of flood consequences.

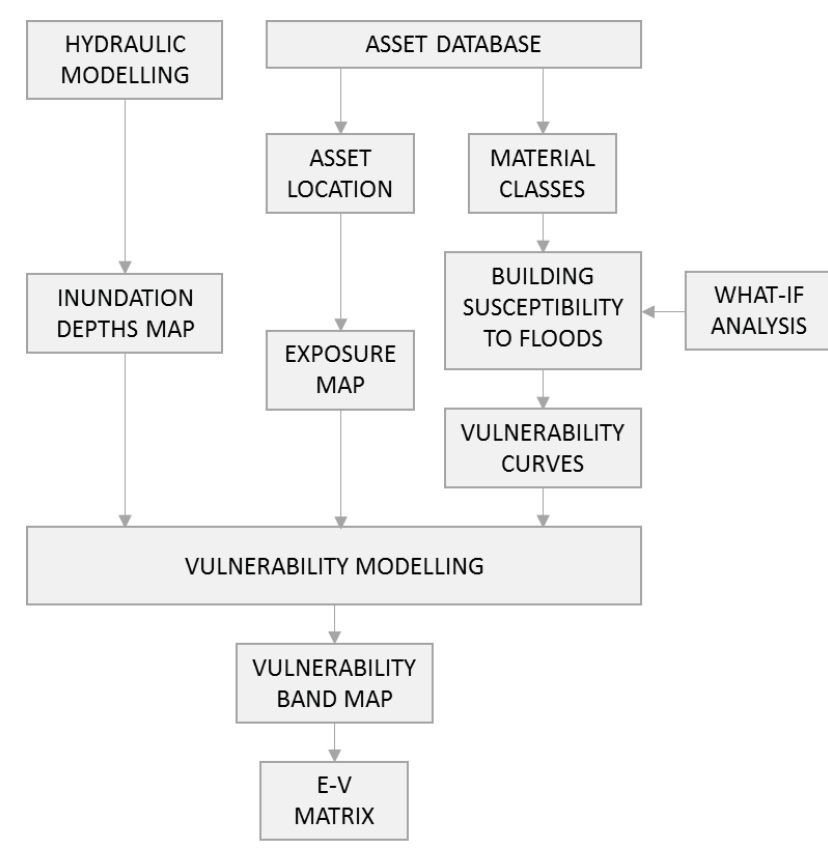

Figure 1. Algorithm for exposure-vulnerability analysis.

\subsection{Hydraulic modelling}

To simulate flood propagation, a 2D model (Aronica et al., 1998) based on De Saint Venant equations has been used.

$$
\begin{gathered}
\frac{\partial H}{\partial t}+\frac{\partial(u h)}{\partial x}+\frac{\partial(v h)}{\partial y}=0 \\
\frac{\partial(u h)}{\partial t}+g h \frac{\partial H}{\partial x}+g h J_{x}=0 ; \frac{\partial(v h)}{\partial t}+g h \frac{\partial H}{\partial y}+g h J_{y}=0
\end{gathered}
$$

where $H(t, x, y)$ is the free surface elevation, $u$ and $v$ are the flow velocity components in $x$ and $y$ directions, respectively, $h$ is the depth of flow, $J_{x}$ and $J_{y}$ are the friction terms in the $x$ and $y$ directions.

The friction terms are represented through the classical Manning-Strickler formulation as:

$$
J_{x}=\frac{n^{2} u \sqrt{u^{2}+u^{2}}}{h^{4 / 3}} ; J_{y}=\frac{n^{2} v \sqrt{u^{2}+u^{2}}}{h^{4 / 3}}
$$

The equations are solved by using a finite element technique with triangular elements to reproduce the complex topography of the built-up areas. More details on the model can be found in Aronica et al. [18].

\subsection{Definition of Exposure's classes}

We adopt Exposure as a global estimation of buildings' socio-economic situation to flood risk, which depends on the property value, the social function, the indirect involvement in economic losses and the population density of the neighbourhood area.

Table 1 shows the building categories based on the above mentioned variables. The main category refers to the membership class considered in the Sicilian Flood Risk Plan. The classification is further refined for residential and public buildings according to their economic or strategic value, which are denoted as second index in the table. The third index describes the detailed type under sub-categories, which are classified depending on their economic or strategic value. This level of detail

\begin{tabular}{|c|c|c|c|}
\hline \multicolumn{2}{|c|}{ CLASS } & \multicolumn{2}{|c|}{ ELEMENTS AT RISK } \\
\hline \multirow{3}{*}{ E1 } & E1.5.1 & \multirow{3}{*}{ Sparse houses } & Single houses \\
\hline & E1.5.2 & & Flats \\
\hline & E1.5.3 & & Villas \\
\hline E2 & E2.2 & \multicolumn{2}{|c|}{ Secondary roads } \\
\hline \multirow{9}{*}{$\mathbf{E 3}$} & E3.1.1 & \multirow{4}{*}{ Small inhabited } & Detached houses \\
\hline & E3.1.2 & & Villas \\
\hline & E3.1.3 & & Farmhouses \\
\hline & E3.1.4 & & Single houses \\
\hline & E3.2.1 & \multirow{4}{*}{$\begin{array}{l}\text { Industrial and craft } \\
\text { settlements }\end{array}$} & Flats \\
\hline & E3.2.2 & & Box/Garage \\
\hline & E3.2.3 & & Sheds \\
\hline & E3.2.4 & & Single houses \\
\hline & E3.2.5 & Sup & kets \\
\hline
\end{tabular}
enables to perform a vulnerability analysis at building scale. 


\begin{tabular}{|c|c|c|c|}
\hline & E3.4 & \multicolumn{2}{|c|}{ Primary roads and escapes } \\
\hline \multirow{11}{*}{ E4 } & E4.1.1 & \multirow{6}{*}{ Residential buildings } & Detached houses \\
\hline & E4.1.2 & & Villas \\
\hline & E4.1.3 & & Flats \\
\hline & E4.1.4 & & Box/Garage \\
\hline & E4.1.5 & & Farmhouses \\
\hline & E4.1.6 & & Single houses \\
\hline & E4.2 & $\begin{array}{l}\text { Civil Protection Areas } \\
\text { and offices }\end{array}$ & $\mathrm{CP}$ and Police offices \\
\hline & E4.3.1 & \multirow{4}{*}{$\begin{array}{l}\text { Significant public } \\
\text { buildings }\end{array}$} & Churches \\
\hline & E4.3.2 & & $\begin{array}{c}\text { Town hall and municipal } \\
\text { offices }\end{array}$ \\
\hline & E4.3.3 & & Schools \\
\hline & E4.3.4 & & Hospitals \\
\hline
\end{tabular}

Table 1. Proposed Exposure classification.

\subsection{Definition of vulnerability curves for buildings}

The basic idea of this study was the derivation of relative vulnerability functions for those sites where both damage data and on-site building inspections are lacking.

Final aim in the derivation of vulnerability curves was to describe possible damages occurring after fluvial floods in urbanized area and to make the curves as generic as possible. While referring to fluvial floods, often characterized by low velocities, another initial condition was to neglect structural damages to the buildings and to consider what happens to non-structural building components.

The first step in synthetic approach is to introduce the building typologies for which derive the curves: buildings are usually distinguished at first in function of their use, than in function of their structural features (e.g. materials, numbers of floors, extension, geometry, age, etc.). This implies strong hypothesis on the buildings' structure and the incorporation of each building presented in the study areas inside these standard pre-defined models.

We considered the damage of non-structural building elements and hypothesized the substitution cost of each element to derive its weight respect to the total substitution costs. To describe the proportional damage relative to each element, a questionnaire was distributed to a team of experts, in particular a team of civil engineers working in Sicily area.

The first step of the analysis consists of deciding which buildings' classes to be included: this distinction is just referred to the buildings' type, because their function has been already considered through their exposure. The same curves can be used for buildings with the same constructive features, even if they have different functions, such as residential or commercial. On the other side, different curves should be used for buildings with the same functions but with different constructive features.

We associated concrete buildings without basement to three finishes types: rich finishes for the building types such as villas and cottages; medium finishes for flats and single houses inside towns; and poor finishes for detached houses and single houses in villages.
After defining these conditions, we analysed the damage of finishes components that included floors, walls, doors and French windows, windows, wiring, water plant, gas plant and services. Their substitution prices were taken from the official price lists and depend on their quality and materials, which in turn were derived from the finishes' class. For example, doors in poor houses were hypothesized to be hollow wooden, while in rich ones were supposed to be in solid wood: these led to different substitution costs that weighed differently in respect to the total costs. These components could also suffer different damages for the same water depths due to the duration of flooding.

Once that all these conditions are defined, a team of experts was asked to describe, according to individual's experience, how each component suffer damages in all the illustrated structures: the results were used to build a series of "partial" vulnerability curves, one for every building element in a particular combination of finishes class and event duration.

The sums of the partial curves that were related to the elements of a building type, each one multiplied for its weight, produced two total vulnerability curves for each building type: one for short and one for long duration hypothesis.

A separate effort needs to be done regarding the vulnerability curves for commercial activities: the majority of them are located in structures with the same materials and building characteristic of residential constructions: the same vulnerability curves can be so used, because in the general analysis their exposure class will play the role to distinguish them from each other.

While considering supermarkets and stores, the stock contents have higher weights in the damage estimation. For these typologies, a double distinction has been made: on one side, they have their own exposure class; on the other side, a vulnerability range varying linearly from 0 to 1 , while the water depths vary from 0 to $60 \mathrm{~cm}$ has been considered. The reason for this last choice was due to the fact that it seemed plausible that when the water depth reach the height of $60 \mathrm{~cm}$, the goods and the machineries (like fridges) contained in supermarkets and stores would be so damaged that a vulnerability value equal to 1 can be associated to them.

\subsection{Vulnerability assessment}

As previously introduced, the input data used for direct impact assessment are the flood inundation depths (inside the buildings), the buildings' exposure classes and the vulnerability curves. Flood inundation depths under various scenarios can be obtained using $2 \mathrm{D}$ hydraulic modelling. Exposure classes can be mapped at microscale (i.e., individual buildings) or at larger scales as land cover classes but, given the detail in exposure classification, the relationship between land cover class and buildings' use should be described. To analyse the flood impact for individual buildings efficiently, we adopted the tool developed by Chen et al. [19] that can assess the vulnerability of each element for multiple flood conditions. 
The results for each flood condition is further summarised to highlight the severity in different exposure category and help decision making. Considering the uncertainties associated with the vulnerability within a catchment, a banded severity in an ExposureVulnerability matrix, as shown in Table 2, was used instead of simple one-to-one relationship curves.

The severity in each exposure type is banded up to five classes (low, moderate, medium, high, extreme), according to the function and importance of the type. For example, hospital would have less tolerance to hazard such that the severity was banded as high even the vulnerability was low. On the contrast, sparse houses could cope with more extreme conditions such that the severity was classified as high for the highest vulnerability class.

\begin{tabular}{|c|c|c|c|c|c|c|c|}
\hline \multirow{4}{*}{ E1 } & E-V & V0 & V1 & V2 & V3 & V4 & V5 \\
\hline & E1.5.1 & & & & & & \\
\hline & E1.5.2 & & & & & & \\
\hline \multirow{5}{*}{ E3 } & E3.1.3 & & & & & & \\
\hline & E3.2.1 & & & & & & \\
\hline & E3.2.2 & & & & & & \\
\hline & E3.2.4 & & & & & & \\
\hline & E.3.2. & & & & & & \\
\hline \multirow{5}{*}{ E4 } & E4.1.1 & & & & & & \\
\hline & E4.1.3 & & & & & & \\
\hline & E4.1.4 & & & & & & \\
\hline & E4.1.6 & & & & & & \\
\hline & $E 4.2$ & & & & & & \\
\hline & E4.3.2 & & & & & & \\
\hline & E4.3.3 & & & & & \\
\hline
\end{tabular}

Table 2. Exposure-Vulnerability banded classification

\section{Case study}

The proposed methodology was applied to the qualitative assessment of flood consequences in Barcellona Pozzo di Gotto (Italy), as shown in Figure 2, a small town hit by an inundation event in 2011.

The town is crossed by the Longano river, whose main branch is about $13.4 \mathrm{~km}$ in length, with a slope 0.18 and levees were built along the river to prevent the city from flooding. Three small bridges and two coverages cross the river and limit its section.

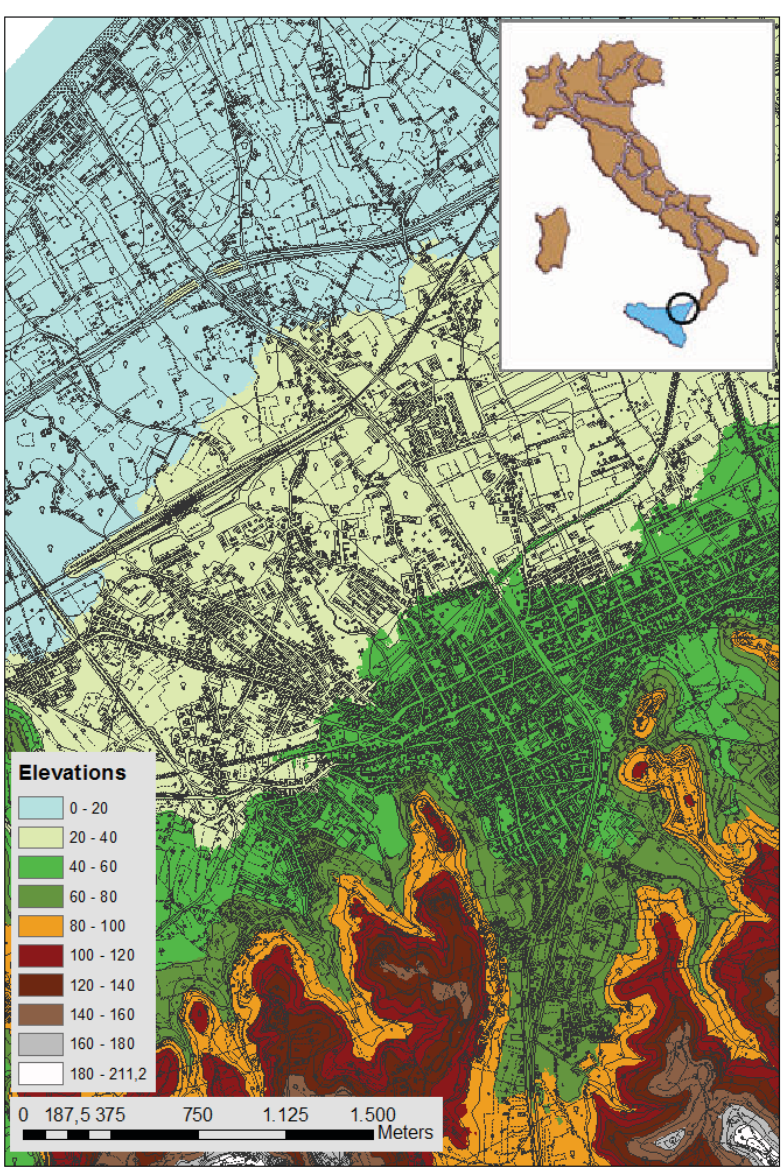

Figure 2. Survey map (1:10000) and DEM (2m resolutions) of Barcellona Pozzo di Gotto urban area.

On 22 November 2011 a thunderstorm brought rainfall $350 \mathrm{~mm}$ in $12 \mathrm{hrs}$ and caused severe inundation in the area. The flow in the river breached firstly from small levee opening and, during the peak discharge, the overtopping at the section near a bridge contributed the majority of inundation volume. Almost 800 buildings were flooded and 100 were used for commercial activities.

The in-depth collection of data on this event made it a good case-study to which applies the proposed methodology to study the flood consequences.

The Municipality investigated the damage situation via questionnaire survey within the affected area and received 600 responses. The questionnaire was previously designed to collect the earthquake damage such that it included questions regarding the description of eventual structural damages and their location, while details regarding flood damage assessment (e.g. wet surface, the water depth inside the building, the presence of a basement) were not considered. This aspect, together with the rough and not regulated compilation, made this data unsuitable for a detailed description or a quantification of damages occurred. The only information derivable from the forms regard the localization of damages among the floors inside the buildings and the non-structural elements involved. 


\subsection{Flood maps}

The variable selected to describe flood hazard was the water depth, which was the only factor whose influence on vulnerability was considered in the vulnerability curves.

The mesh boundary was based on the morphology of the study area to cover alluvial fan. The blockage effect of buildings on flood propagation was reflected by assuming the building walls as internal barriers. The total domain area was about $1.74 \mathrm{~km} 2$ and discretized in 53081 triangular elements. The geometric features $(x, y, z$ coordinates) of 31814 nodes have been derived from the Digital Elevation Map (DEM) with $2 \mathrm{~m}$ resolution.

On a GIS Platform, the inundation depths inside the buildings have been derived as the mean inundation depth value along their contours.

\subsection{Exposure classification}

Thanks to field surveys and Google Street, the Exposure classification was carried out at the micro-scale for buildings in the study area and results have been reported in Figure 3.

In case of mixed-use (residential and commercial) buildings, the classification referred to the use at the ground floor (the water depths occurred in past flood events, in fact, has not been so high to reach the raised floors).

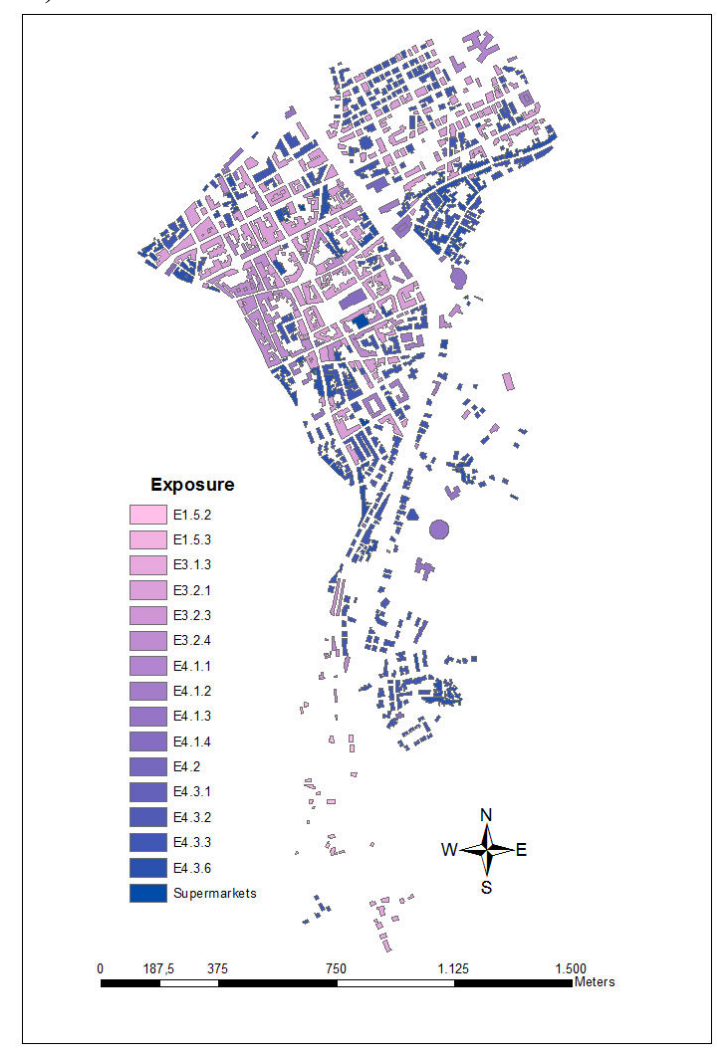

Figure 3. Exposure classification map

\subsection{Vulnerability curves}

Through the questionnaire, a team of experts described the proportional damage to building elements (floors, walls, doors, windows, French windows, wiring, hydraulics, gas systems, water systems, bathroom fixtures) with various water depths.

The questions developed were intentionally open and generic, in order to allow each expert to describe any result from personal experiences. They were asked to refer to a reinforced concrete building subjected to flooding without suffering any structural damage during a flood event.

The hypothesis to neglect contents damage was adopted because of the impossibility to validate the results because of the absence of correspondent data. Moreover, in the optic of a general moving to the adoption of insurance policies for natural hazards, that will not cover damage to contents, or will consider them as a percentage of damage to structures, the derivation of relative damage curves for buildings' contents would be premature and maybe not useful.

Because many interviewed indicated the influence on damage of flood duration and of interior finish materials (e.g., difference between permeable or gypsum plaster, or between wooden or aluminium windows, or between floors laid on mortar or concrete, etc.), these aspects were considered. In fact, as descripted in section $\mathrm{xx}$, short and long duration (more than 36 hours) event were distinguished and poor, intermediate and rich materials too.

To derive the total vulnerability each element was assigned a weight in function of its substitution cost respect to the total substitution costs. Using the official price list for Sicily, the calculations has been referred to a standard room (20 square meters) with: a door, a window, a French window, 5 electrical outlets at height $30 \mathrm{~cm}, 2$ switches and other 3 electrical outlets T height $110 \mathrm{~cm}$.

Standard weights of 0.1 were assigned to the gas and the water systems, because there can be too many configuration which their elements may assume and it would need a proper what-if analysis with field data to decide a plausible one.

The weights of some elements change with the water depth. The walls, for example, need to be completely repainted independently from the water depth reached within the room, but the quantity of plaster which must be scraped, led to landfill and substituted depends on the water depth..

Once the different weights (for water depth less than or equal to $50 \mathrm{~cm}$, between 50 and $100 \mathrm{~cm}$, between 100 and $150 \mathrm{~cm}$, greater than $150 \mathrm{~cm}$ ) were derived, we put them together in two curves distinguishing between short and long flood duration. 


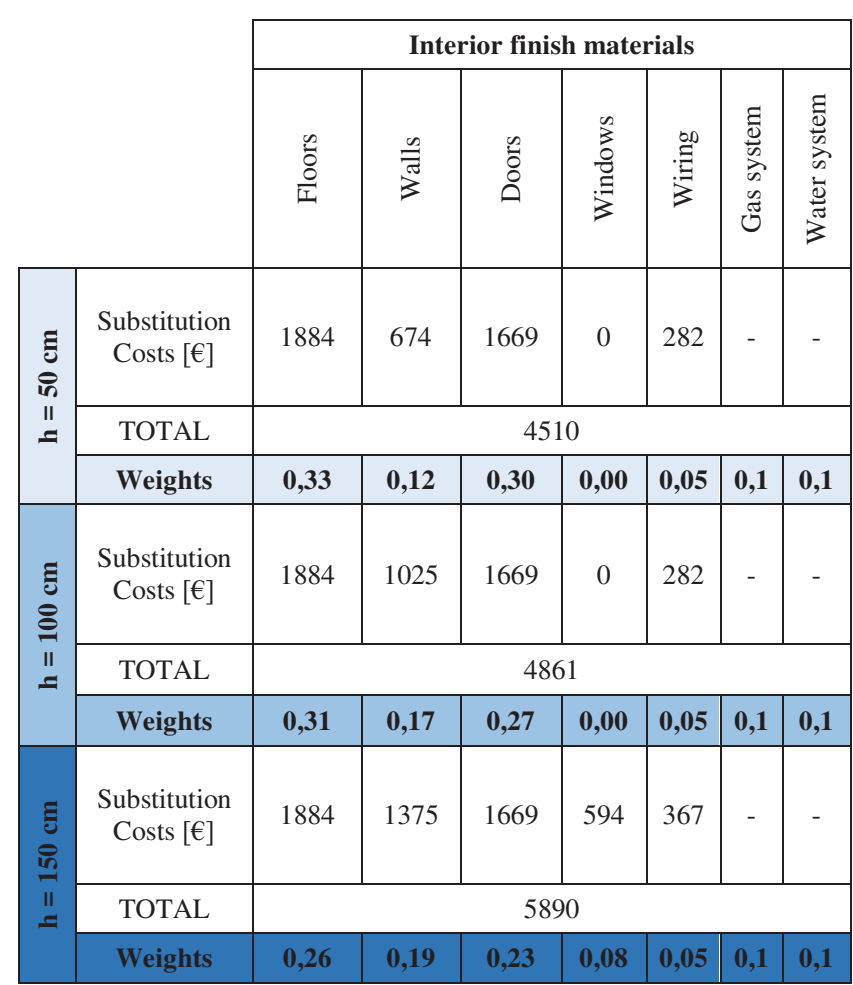

Table 3 Derivation of buildings' elements' weights.

\subsection{Vulnerability analysis}

We further combined the hazard information, assets exposure, and vulnerability curves to determine the vulnerability of each building under the given flood conditions. The results were categorised into bands for prioritising assessment. In particular, vulnerability assessment has been implemented in a GIS environment relating building use and building internal inundation depth to the appropriate vulnerability curve.

Buildings data have been associated to their exposure classes, which correspond to the vulnerability curve for that building typology such that the vulnerability for each building can be calculated by using these functions to relate the flood depth to the damage.

Given the numerous sources of uncertainty in vulnerability assessment, it was decided to group its values in classes. As in Thakur et al. (2012), vulnerability intervals of 0.2 have been chosen to describe the progressive suffered damage.

\section{Discussion and conclusions}

\subsection{Vulnerability curves}

Figures 4 and 5 show the vulnerability curves for poor materials and different flood durations. Under the curves, different colours have been used to distinguish the contribution of each element to the total vulnerability. As expected from previous considerations, floors contribution decreases with growing water depths, while windows contribution starts for water depths higher than $90 \mathrm{~cm}$.

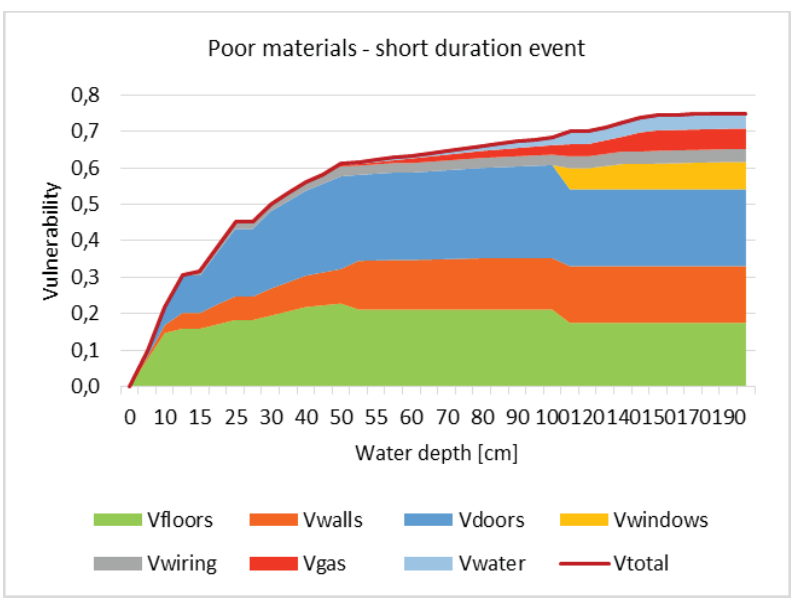

Figure 4. Vulnerability curve for buildings "poorly finished" and short duration event, with buildings' elements' contributions.

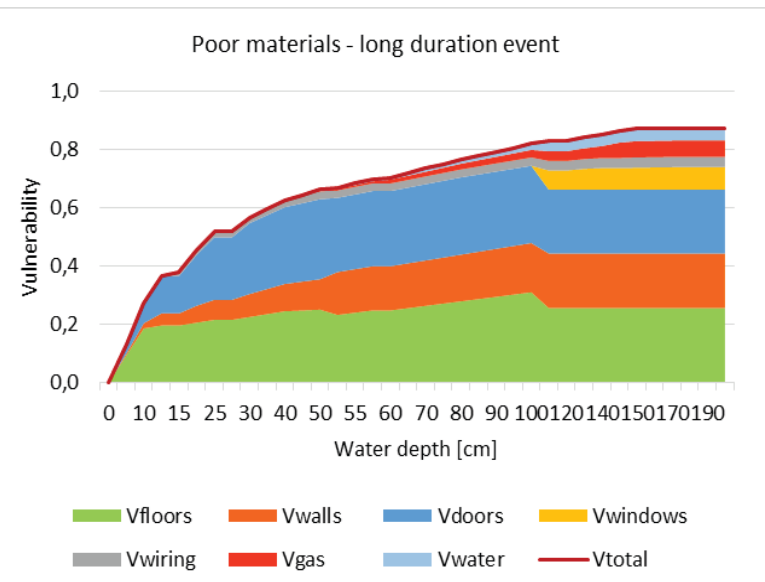

Figure 5. Vulnerability curve for buildings "poorly finished" and long duration event, with buildings' elements' contributions.

The highest value of the total vulnerability, as can be seen in the figure, was almost equal to 0.7 . It was due to derived curves associated to each single element. As a synthesis of the questionnaire answers, none of them reached the vulnerability value of 1 (none of the experts experienced an inundation depth which caused the necessity of completely substitution of an element). This can be due to the fact that we asked to ignore structural damages: it is easy to imagine that a flood destroys its structural elements before causing so huge damages to all non-structural elements.

A double confront can be done about the curves based on their dependence on event duration, their variation with materials' improvement and how this influence also the passage between short and long duration. Figures 6 and 7 show the curves for three classes of materials' quality, grouped for short and for long duration event. The passage from poor to rich materials, as expected, corresponds to a decrease in relative damage, as better material suffer less flood damage in respect to poor ones.

This reduction is higher in short duration events, because poor materials suffer huge damages yet for short duration of water contacts, while good materials often need a simple clean-up intervention in these cases. It is 
instead lower for long duration events, because over a certain threshold poor materials reach a maximum damage (for us, it corresponds to the necessity of substitute the corresponding element), while rich ones go on suffering the consequences of water contact.

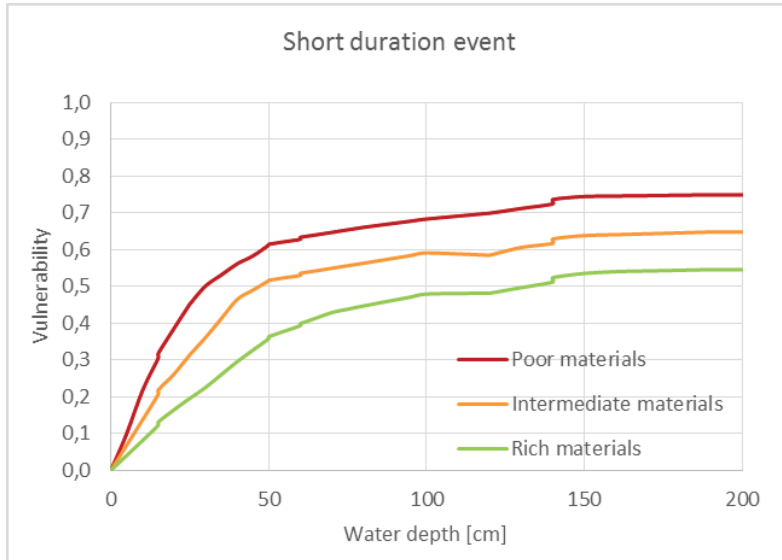

Figure 6. Comparison among curves for poorly finished, intermediate and richly finished buildings (short duration event).

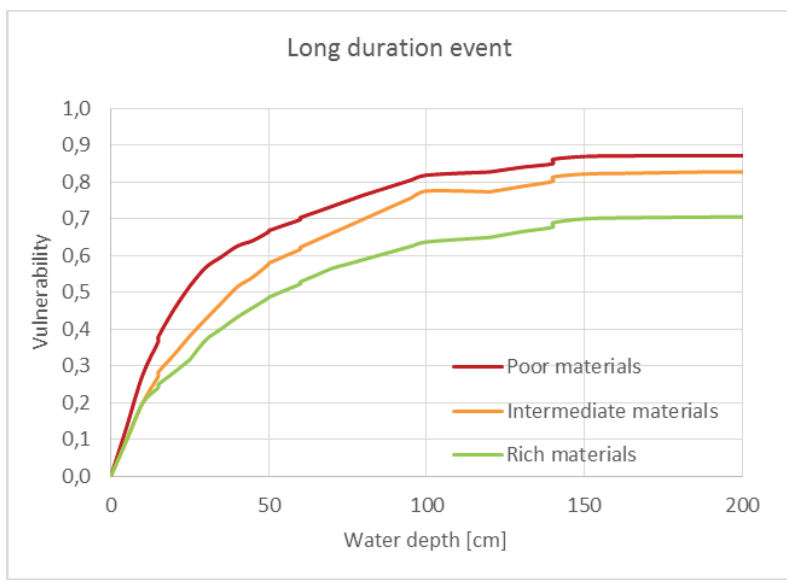

Figure 7. Comparison among curves for poorly finished, intermediate and richly finished buildings (long duration event).

Although this damage reduction, the passage to rich materials implies also the disruption of more expensive objects, so that passing from relative to absolute curves (by multiplying them for elements' values), this tendency could invert.

\subsection{Exposure-Vulnerability analysis}

Although the exposure classification does not allow for a quantitative estimation of flood risk, it provides strategically significant indications. The comparison of exposure and vulnerability maps can identify immediately the buildings or sensitive areas that are associating with high vulnerability or, vice versa. Moreover, as same vulnerability curves are associated to same featured buildings, the only way to know if they cover different roles is consulting their exposure class.

The results of vulnerability analysis have been reported both in maps and in an Exposure-Vulnerability matrix, which summarises the overall situation of a catchment that can be compared between different scenarios. In each cell of the matrix, it can be seen which percentage of the total number of buildings (739) is associated to each vulnerability class, distinguished for the different exposure classes. The coloured bands, to be distinguished from the vulnerability ones, help in identifying areas that are more sensitive. They change from green to dark red, as the E-V classification worsen: this happens either for "low" exposure/high vulnerability classes, or for "high" exposure/low or high vulnerability ones.

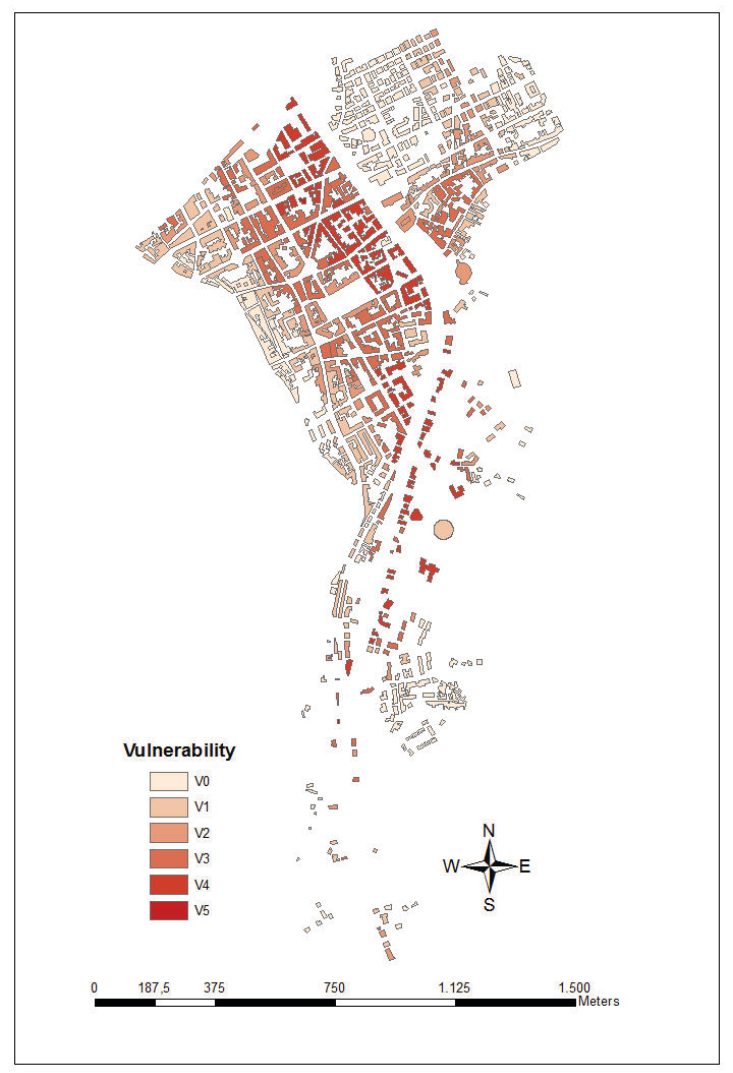

Figure 8. Vulnerability map.

\begin{tabular}{|c|c|c|c|c|c|c|c|}
\hline & E-V & vo & V1 & V2 & V3 & V4 & V5 \\
\hline \multirow{2}{*}{ E1 } & E1.5.1 & - & $0.14 \%$ & $0.14 \%$ & - & $0.14 \%$ & \\
\hline & E1.5.2 & $1.08 \%$ & $0.27 \%$ & $0.14 \%$ & $0.27 \%$ & $0.41 \%$ & \\
\hline \multirow{5}{*}{ E3 } & E3.1.3 & $0.27 \%$ & $0.27 \%$ & $0.41 \%$ & $0.27 \%$ & $0.14 \%$ & \\
\hline & E3.2.1 & $0.81 \%$ & $1.49 \%$ & $0.14 \%$ & $0.41 \%$ & $2.44 \%$ & $0.54 \%$ \\
\hline & E3.2.2 & $0.41 \%$ & $1.76 \%$ & $0.27 \%$ & $0.41 \%$ & $0.68 \%$ & \\
\hline & E3.2.4 & $7.04 \%$ & $2.84 \%$ & $3.65 \%$ & $5.14 \%$ & $5.68 \%$ & $2.71 \%$ \\
\hline & E.3.2.5 & - & - & $0.14 \%$ & $0.27 \%$ & $0.14 \%$ & \\
\hline \multirow{7}{*}{ E4 } & E4.1.1 & $2.17 \%$ & $1.89 \%$ & $0.95 \%$ & $2.03 \%$ & $3.38 \%$ & $0.41 \%$ \\
\hline & E4.1.3 & $16.51 \%$ & $7.58 \%$ & $4.19 \%$ & $4.33 \%$ & $6.50 \%$ & $3.79 \%$ \\
\hline & E4.1.4 & $0.14 \%$ & - & - & - & & \\
\hline & E4.1.6 & $0.14 \%$ & $0.14 \%$ & $0.14 \%$ & $0.14 \%$ & $0.41 \%$ & $0.27 \%$ \\
\hline & E4.2 & - & $0.41 \%$ & - & - & $0.14 \%$ & \\
\hline & E4.3.2 & - & $0.27 \%$ & $0.14 \%$ & $0.54 \%$ & $0.68 \%$ & $0.14 \%$ \\
\hline & E4.3.3 & $0.27 \%$ & $0.27 \%$ & $0.27 \%$ & $0.14 \%$ & $0.27 \%$ & $0.54 \%$ \\
\hline
\end{tabular}

Table 4 Exposure-Vulnerability matrix with banded vulnerability assessment (2011 flooding event) 


\section{Conclusion}

In the study, we presented a novel approach to evaluate the building vulnerability during a flood event where the detailed relationships between hazard and vulnerability are absent.

The construction of E-V matrix allows us a better understanding of situation of a catchment (and the possible consequences of a flood event) to priorities the resources and effort to the department that are in charge of protecting the most vulnerable type of buildings. It also help us evaluate the effectiveness of non-structural measures before setting up the flood mitigation strategies.

\section{References}

1 Egli, T. (2002) Non Structural Flood Plain Management: Measures and their Effectiveness, International Commission for the Protection of the Rhine (ICPR), Koblenz, Germany.

2 Lasage, R., Veldkamp, T. I. E., De Moel, H., Van, T. C., Phi, H. L., Vellinga, P. and Aerts, J. (2014) Assessment of the effectiveness of flood adaptation strategies for HCMC. Nat. Hazards Earth Syst. Sci. 14, 1441-1457.

3 Kreibich, H., Thieken, A., Müller, M. and Merz, B. (2005) Precautionary measures reduce flood losses of households and companies-insights from the 2002 flood in Saxony, Germany. Floods Def. Manag. 851-859.

4 Kron, W. (2005) Flood risk = hazard center dot values center dot vulnerability. Water Int. 30, 58-68.

5 UNISDR. (2009) 2009 UNISDR Terminology on Disaster Risk Reduction, United Nations International Strategy for Disaster Reduction, United Nations, Geneva, Switzerland.

6 Birkmann, J. (2006) Measuring Vulnerability to Natural Hazards: Towards Disaster Resilient, Societies. New York: United Nations Publications.

7 Füssel, H.-M. (2007) Vulnerability: A generally applicable conceptual framework for climate change research. Glob. Environ. Change 17, 155-167.

8 Hufschmidt, G. (2011) A comparative analysis of several vulnerability concepts. Nat. Hazards 58, 621-643.

9 Fuchs, S., Heiss, K. and Hübl, J. (2007) Towards an empirical vulnerability function for use in debris flow risk assessment. Nat. Hazards Earth Syst. Sci. 7, 495-506.

10 HR Wallingford. (2000) National appraisal of assets at risk from flooding and coastal erosion, DEFRA.

11 Sayers, P. B., Hall, J. W. and Meadowcroft, I. C. (2002) Towards risk-based flood hazard management in the UK. Proc. Inst. Civ. Eng.-Civ. Eng. 150, 36-42.

12 Hall, J. W., Dawson, R. J., Sayers, P. B., Rosu, C., Chatterton, J. B. and Deakin, R. (2003) A methodology for national-scale flood risk assessment. Proc. Inst. Civ. Eng.-Water Marit. Eng. 156, 235-247.
13 Kok, M., Huizinga, H. J., Vrouwenfelder, A. C. W. M. and Berendregt, A. (2004) Damage and casualties caused by flooding, Highways and Hydraulics Engineering Department.

14 Meyer, V. and Messner, F. (2005) National Flood Damage Evaluation - Methods A Review of Applied Methods in England, the Netherlands, the Czech Republic and Germany. UFZ-Diskuss. 212005.

15 Varnes, D. J. (1984) Landslide hazard zonation: a review of principles and practice.

16 Fell, R. (1994) Landslide risk assessment and acceptable risk. Can. Geotech. J. 31, 261-272.

17 Regione Sicilia. (2004) Piano Stralcio di bacino per l'Assetto Idrogeologico della Regione SicilianaRelazione Generale.

18 Aronica, G., Tucciarelli, T. and Nasello, C. (1998) 2D multilevel model for flood wave propagation in flood-affected areas. J. Water Resour. Plan. Manag. 124, 210-217.

19 Chen, A. S., Hammond, M. J., Djordjević, S., Butler, D., Khan, D. M. and Veerbeek, W. (2016) From hazard to impact: the flood damage assessment tools for mega cities. Nat. Hazards in press. 